\title{
Coincident Alcohol Dependence and Depression Increases Risk of Suicidal Ideation among Army
} National Guard Soldiers

Gregory H Cohen, MPhil, MSW $(1,2)$

David Fink, MPH (2)

Laura Sampson, AB (1)

Marijo Tamburrino, MD (3)

Israel Liberzon, MD (4)

Joseph R. Calabrese, MD (5)

Sandro Galea, MD, DrPH $(1,2)$

(1) Boston University School of Public Health, 715 Albany St., Boston, MA 02118 (2) Columbia University, Mailman School of Public Health, 722 West 168th Street, NY, NY, 10032, (3) University of Toledo Health Science Center, 2801 W. Bancroft, Toledo, OH 43606, (4) University of Michigan, 4250 Plymouth Road, Ann Arbor, MI 48109, (5) Department of Psychiatry, University Hospitals Case Medical Center, Case Western Reserve University, 11400 Euclid Ave Ste 200, Cleveland, OH 44106

\section{Running Head: Coincident Alcohol Dependence and Depression}

Words: 3471

\section{Conflict of Interest Declaration: None}

Financial Support: Department of Defense Congressionally Directed Medical Research Program W81XWH-07-1-0409, the "Combat Mental Health Initiative"

Previous Presentations: None

Corresponding Author: Gregory H. Cohen 


\section{ABSTRACT}

Purpose: Suicide rates among military service members have risen dramatically, while drivers remain poorly understood. We examined the relationship between coincident alcohol dependence and depression in shaping risk of suicidal ideation among National Guard forces.

Methods: We performed a longitudinal analysis using a randomly selected, population-based sample of Ohio Army National Guard soldiers. Telephone-based surveys of 1582 soldiers who participated in both wave 1 (2008-2009) and wave 2 (2009-2010) were analyzed.

Results: Odds ratios (ORs) for suicidal ideation among those with vs. without alcohol dependence were similar among non-depressed [OR=3.85 (95\% Confidence Intervals $(\mathrm{Cl})=1.18-12.52)]$ and depressed individuals $[\mathrm{OR}=3.13(95 \% \mathrm{Cl}=0.88-11.14)]$; multiplicative interaction was not observed. In contrast, the risk differences (RD) among those with vs. without alcohol dependence diverged for those without depression $[\mathrm{RD}=0.04(95 \% \mathrm{Cl}=0.02-0.07)]$ compared to those with depression [RD $0.11(95 \% \mathrm{Cl}=0.06$ $0.18)]$; strong evidence of additive interaction was observed.

Conclusions: We found that alcohol dependence and depression interact statistically in shaping risk for incident suicidal ideation among Army National Guard service members. A high-risk prevention approach including population-based screening for suicidality among patients with alcohol dependence, depression, and particularly those with both conditions is warranted in military populations. 


\section{INTRODUCTION}

Suicide and suicide risk among U.S. military forces and veterans have increased substantially in the last decade $[1,2]$. Suicide in service members has historically been lower than that in the general population [3]; however, this gap has diminished substantially in recent years among service members from Operation Enduring Freedom (OEF), Operation Iraqi Freedom (OIF), and Operation New Dawn (OND) [4-7]. The increase in suicide rates has come despite the investment of tremendous resources aimed at reducing this problem [8].

The suicide rate among Army National Guard soldiers has, in a divergence from earlier trends, recently exceeded that of Active Duty Army and Army Reserves [7,9,10], adjusting for military subcomponent demographic composition. In 2010 and 2013, the suicide rate among Army National Guard soldiers exceeded that of Active Duty Army and Army Reserves $[7,9,10]$. Surveillance data from 2014 suggests this excess risk among Army National Guard service members may be leveling off [7], but this divergence nonetheless raises concern. Furthermore, rates of suicide in the Army National Guard have consistently remained higher than age-matched civilians, aside from a slight dip in 2013 [11].

Sociodemographic predictors of suicide risk appear to be consistent among both reservists and active duty service members $[9,7,10,12]$. Despite conflicted findings across individual studies[5,10,6,13], a recent meta-analysis suggests that the links between deployment or combat deployment and suicide in OEF/OIF/OND service members are weak to non-existent, whereas the link to combat exposure is supported by data but weak [14]. Lower rank $[5,6,13]$ has also been associated with increased suicide risk, and while some studies have linked greater suicide risk to men $[7,10,13]$, others have found the opposite [5,15].

Depression is the most common predictor of suicidality both in civilian [16-18] and military populations $[5,13,19,20]$, estimated to be prevalent among $2.7 \%$ to $14.7 \%$ of OEF/OIF/OND National Guard and reserves forces [21]. Given the 3-fold magnitude of associated risk for suicide [13] and suicidal ideation [5] among service members, depression remains an important target for suicide prevention.

Alcohol misuse is another common condition among military service members, ranking second only to depression in its association with suicide. Whereas a few studies have examined the influence of alcohol misuse $[12,13,22]$, most literature on suicide and suicidality in OEF/OIF/OND service members has focused almost exclusively on depression and PTSD $[23,24]$ as causes, largely considering alcohol misuse only peripherally, as a covariate or comorbidity. Within the general population, alcohol use disorders and acute alcohol intoxication are strongly associated with suicide attempts and suicide [2527]. Both acute intoxication and chronic use of alcohol (including dependence) are associated with increased risk of suicide and attempted suicide $[25,27,28]$. Alcohol use disorders are among the most common diagnoses associated with suicide, and are implicated in approximately one quarter of suicides [25].

Of particular concern, the estimated prevalence of alcohol use disorders among Reserve and National Guard forces serving during OEF/OIF/OND was 14 to 15\% [21]. Among the reserve component, deployment with combat exposures was associated with higher risk of new-onset alcohol misuse, with Army National Guard and Reserve forces having a higher prevalence of new-onset alcohol misuse than Air Force, and Navy/Coast Guard and a lower prevalence than Marines [29]. Among service members with alcohol misuse, the increased risk of suicidal ideation and suicide are approximately-3 fold $[13,19]$. 
Alcohol dependence and depression are clearly risk factors for suicidal ideation in isolation. We hypothesize that in comorbid presentations they interact in shaping risk of suicidal ideation. Evidence from civilian studies $[18,30]$ suggests that comorbid alcohol dependence and depression act together in shaping suicide risk. These civilian findings, along with the common occurrence and comorbidity of both conditions among military service members [31,32], warrant investigation of their interaction effects in predicting suicidal ideation among service members.

Accordingly, the present investigation aimed to estimate among Army National Guard forces, (1) the effect of alcohol dependence on risk of incident suicidal ideation; (2) the effect of depression on risk of incident suicidal ideation; and (3) the interaction between alcohol dependence and depression on risk of incident suicidal ideation. We utilize an Ohio Army National Guard (OHARNG) sample and adjust for the influence of sociodemographic characteristics and military service factors. In the interest of temporal proximity, we focus on past year depression and alcohol dependence. In order to examine the degree to which alcohol dependence and depression act together in predicting suicidal ideation, we examine statistical interaction on both the additive and multiplicative scales.

\section{MATERIAL METHODS}

Population

We conducted a longitudinal investigation of a sample of the OHARNG. Our sample was drawn from 10,778 soldiers serving in the OHARNG as of June 2008, and the 1,792 who enlisted between then and February 2009. In total, 12,225 OHARNG soldiers were invited to participate through a 2-stage process including an opt-out alert letter directly from the OHARNG, and a phone call to obtain consent to participate in a phone interview. 1013 (8\%) soldiers opted out, and 345 (2.8\%) were excluded due to lack of a current address. After 3 weeks, the OHARNG sent us contact information for 11,212 soldiers who did not opt-out. We called 6,514 (58.1\%) working numbers: 218 (3.3\%) were not eligible (i.e. too young, retired, non-English speaker, hearing problems); 1,364 (20.9\%) did not wish to participate; and $2316(35.6 \%)$ were not contacted before the cohort closed. Service members deployed at the time of initial contact were called again following return from deployment. The final baseline study sample included 2616 OHARNG soldiers, men and women aged 17 years or older, who were capable of informed consent. Soldiers could have been 17 as opposed to 18 because emancipated minors are considered adults by the military. The overall cooperation rate (defined as number consented divided by number of successfully contacted numbers)[33] was $68.2 \%$, and the response rate was $43.2 \%$ (defined as those who completed the survey plus those who consented but were ineligible, dived by the number of working numbers minus those disqualified)[33]. A second wave of interviews was conducted 1 year later and included 1,767 (67.5\%) of those interviewed at baseline; we excluded $183(10.4 \%)$ with a lifetime history of suicidal ideation at baseline. Our final analytic sample included 1582 soldiers.

Participants were administered a 60-minute telephone survey, including questions on military history and experiences, health status and medical history, social support, deployment- and civilianrelated trauma and psychopathology, mental health service use, and demographic characteristics. Bachelors-level lay interviewers, trained and managed by professional survey firm Abt-SRBI ( $>25$ years of experience interviewing military personnel) interviewed participants using computer-assisted telephone interviewing techniques. Interviewers received extensive training on working with military service members and conducting psychiatric symptom interviews. Interviewers obtained participant 
consent from at the start of each interview and offered financial compensation for their time. All human subjects procedures were overseen and approved by the Institutional Review Boards of Columbia University, Case Western Reserve, University of Toledo, University of Michigan and the Department of Defense.

\section{Traumas}

Deployment-related traumatic event experiences were identified with a list of 21 traumatic events specific to military service [34] and asked in reference to most recent deployment. Traumatic event experiences that may have occurred either within or outside of military deployment experiences were additionally identified using a list of 25 traumatic events [35]; if participants endorsed any of these events, they were asked whether the event(s) happened in relation to their most recent deployment. Therefore, we assessed for a total of 46 events related to most recent deployment and 25 events that were not.

\section{Diagnoses}

We used the Patient Health Questionnaire (PHQ-8 version) [36] to evaluate depression symptoms. Each of the eight questions asked about symptom frequency within the prior 2 weeks, and possible responses included 0 (not at all), 1 (several days), 2 (more than half the days) and 3 (nearly every day), with total scores ranging from 0 to 24 [37]. We added questions to assess timing, duration, severity of illness, and disability resulting from symptoms. Major depressive disorder (MDD) was assessed using DSM-IV criteria [38] and considered present if five or more of the eight depressive symptoms were present at least "more than half the days" in the past two weeks, and one of the symptoms was depressed mood or anhedonia. Other depressive disorder (ODD) was considered present if 2-4 depressive symptoms were present at least "more than half the days" in the past two weeks, and one of the symptoms was depressed mood or anhedonia. Depression cases included individuals who met criteria for either MDD or ODD and reported that his/her symptoms seemed to have occurred together. We included questions to assess the duration and grouping of symptoms. Based on a validation testing of 500 individuals who completed both a telephone and clinical sample interview, we found that excluding the impairment question maximized sensitivity and specificity in our sample [39], and thus did not include it in our case definition. Our telephone-based definition of depression is highly specific (83\%) and moderately sensitive (51\%), with a positive predictive value (PPV) of 0.46 and a Chronbach's alpha (standardized) of 0.66 [39].

Alcohol dependence was assessed using the Mini-International Neuropsychiatric Interview (MINI) [40] based on DSM IV criteria [38]. Alcohol dependence was diagnosed among those who met at least three of seven substance dependence criteria that include tolerance (criteria 1), withdrawal (criteria 2), and compulsive use (criteria 3-7). Participants were asked whether these symptoms had occurred within the past month and year. Our telephone-based alcohol dependence definition is highly specific (81\%) and moderately sensitive (60\%), with a PPV of 0.46 and a Chronbach's alpha (standardized) of 0.76 [39].

Suicidal ideation was assessed using a question from the PHQ-9 [37], which asks participants about "thoughts that you would be better off dead or of hurting yourself in some way, within the past 30days?" and "within the past year?" For this investigation, we were interested in predicting incident or new-onset suicidal ideation at wave 2 , within the prior year. Accordingly, we omitted this question from 
our depression measure to avoid overlapping model constructs. Our telephone-based suicidal ideation item was highly specific (0.87), with low sensitivity (0.32), and a PPV of 0.55 [39].

\section{Statistical Analyses}

All analyses were weighted to (1) calibrate our estimates to reflect the distributions of gender, age, race/ethnicity, education, marital status, rank, deployment history, and years served in the military for the OHARNG universe we sampled from, and (2) to adjust for the same factors as predictors of unit nonresponse at one-year follow-up. Design effects for variables included in this analysis are presented in table 1. Chi-squared tests were used to examine proportions of incident suicidal ideation at one-year follow-up, within strata of our independent variables. We used logistic regression models to illustrate bivariate relationships between alcohol dependence, depression, and other putative predictors of incident suicidal ideation such as demographics, military rank, lifetime trauma, and past year trauma. We examined interaction between alcohol and depression in predicting suicidal ideation by examining relative measures - odds ratios of suicidal ideation for those with alcohol dependence with and without depression, and with absolute measures - by plotting conditional risks of suicidal ideation across interaction strata. Finally, we quantitatively examined multiplicative and additive interaction between depression and alcohol dependence using a cross-product term, and by calculating the relative excess risk of interaction (RERI), the Attributable Proportion due to Synergy (AP), and the Synergy Index (SI) [41]. We were particularly interested in investigating departure from additivity, as this is consistent with what is known as public health interaction - a situation in which predicting risk for a given outcome depends on knowing the status of each interaction exposure factor $[42,43]$. In such a scenario, the removal of one factor alone may have a large impact on the population risk for a given outcome. Statistical analyses were performed with SUDAAN 11 [44] and SAS 9.4 [45].

\section{$\underline{\text { RESULTS }}$}

As shown in Table 1, the final study population was predominantly male (86.3\%) and white (88.9\%). Approximately half had some college or technical training $(48.2 \%)$ and nearly half were married (40\%); median age of soldiers was between 18-24 (37.3\%). Most soldiers were enlisted personnel (90.2\%), had 1-4 deployments (58.9\%), 3-6 lifetime traumatic events at baseline (29.4\%), and 0 traumatic events between baseline and follow-up (49.7\%). At baseline, $6.4 \%$ of our sample had current alcohol dependence, and $10.5 \%$ had current depression.

Incident suicidal ideation was present among 42 or $2.47 \%$ (1.68-3.26) of soldiers at follow-up. Table 1 shows that suicidal ideation at wave 2 was associated with alcohol dependence at baseline (8.97\%; $p=0.03)$, and depression at baseline $(8.09 \% ; p<0.001)$. In unadjusted logistic regression models, alcohol dependence (odds ratio $[\mathrm{OR}]=4.76$; 95\% confidence interval $[\mathrm{Cl}]=2.05-11.06$ ) and current depression $(\mathrm{OR}=4.77 ; 95 \% \mathrm{Cl}=2.37-9.63)$ were both associated with incident suicidal ideation at a similar magnitude (table 2). None of the other predictors evaluated in table 2 were associated with our outcome at a statistical significance level of $p<0.05$.

To evaluate and compare additive vs. multiplicative interaction, we first calculated unadjusted odds ratios and risk differences for those without vs. with alcohol dependence, across strata of depression status. Odds ratios (ORs) for suicidal ideation among those with vs. without alcohol dependence were similar among non-depressed $[\mathrm{OR}=3.85(95 \% \mathrm{Cl}=1.18-12.52)]$ and depressed 
individuals [OR $=3.13(95 \% \mathrm{Cl}=0.88-11.14)$ ]. Risk differences $(\mathrm{RD})$ for suicidal ideation among those with vs. without alcohol dependence diverged for those without depression $[R D=0.04(95 \% \mathrm{Cl}=0.02$ 0.07)] compared to those with depression [RD 0.11(95\% $\mathrm{Cl}=0.06-0.18)]$.

Formal and descriptive analyses of interaction are presented in Figure 1. To descriptively characterize the risk of suicidal ideation within interaction strata, we calculated conditional risks of incident suicidal ideation in those with neither condition $(0.02 ; 95 \% \mathrm{Cl}: 0.01-0.02)$, with alcohol dependence but no depression (0.06; $95 \% \mathrm{Cl}: 0.02-0.16)$, with depression but no alcohol dependence (0.06; 95\% Cl: $0.03-0.12)$, and with both conditions (0.17; $95 \% \mathrm{Cl}: 0.07-0.38)$. To assess multiplicative interaction, we fit a multiple logistic regression model including both alcohol dependence $(\mathrm{OR}=3.51$; $95 \% \mathrm{Cl}=1.45-8.49)$ and depression $(\mathrm{OR}=3.93 ; 95 \% \mathrm{Cl}=1.90-8.12)$; we tested a cross-product term for alcohol dependence and depression in a multiple logistic regression model including both conditions, and this term was statistically non-significant (beta coefficient $=-0.21, p=0.82$ ), suggesting absence of multiplicative interaction. To test additive interaction we computed the RERI, AP, and S for alcohol dependence and depression, finding strong evidence of interaction on the additive scale (RERI = 5.978(95\% Cl: 0.364-11.591), AP = 0.461(95\% Cl: 0.199-0.723), and S = 1.998(95\% Cl: 1.163-3.434)).

\section{DISCUSSION}

Using a sample of Ohio Army National Guard soldiers, we found that alcohol dependence and depression interact to place a soldier at greater risk of subsequent suicidal ideation. Each condition alone was associated with risk, but the presence of both conditions together had a stronger effect than the sum of their risks in isolation, providing evidence of positive additive interaction. This has implications for screening of soldiers and may help focus our efforts to reduce suicide rates among reservists.

Although no other studies to our knowledge have examined the link between coincident alcohol dependence and depression on incident suicidal ideation in the military prospectively, our key findings are in line with findings in other military samples that have examined the links between each condition individually. Our finding of an association between alcohol dependence and suicidal ideation is consistent with that of a prior National Guard sample that demonstrated this association using crosssectional data [46]. Our finding of an association between depression and suicidal ideation is consistent with findings in mixed component samples of OEF/OIF veterans $[19,22]$ and with findings in the 2008-2014 Department of Defense Suicide Event Reports [7,9,10]. Griffth [12], who examined suicide in a national sample of the Army National Guard using suicide data spanning from 2007-2010, found that an alcohol abuse history was prevalent among $12-17 \%$ of suicide cases, but did not specifically examine alcohol dependence.

Our results are consistent with an extensive civilian population literature demonstrating the link between alcohol dependence and suicidality, both cross-sectionally and prospectively $[28,47,48]$, and the well-established link between depression and suicidality [49]. Indeed, Kessler and colleagues [17] found that both alcohol dependence and depression were independently associated with suicidal ideation and suicide attempts in cross-sectional data from a representative sample of the general US population. Finally, our findings of positive additive interaction between alcohol dependence and depression in suicidal ideation risk are consistent with civilian studies $[18,30]$ demonstrating an increased risk of suicidal ideation and behavior for those with both conditions. The RERI (part of the total effect due to interaction) of 5.978 confirms positive additive interaction as the point estimate and 
its confidence intervals exceed 0 ; the AP of 0.461 tells us that almost $50 \%$ of the risk of suicidal ideation among those with both conditions is attributable to the synergy between those conditions; the $S$ (ratio of combined and individual effects) of 1.998 confirms positive additive interaction, as this point estimate and its confidence intervals exceed $1[42,50]$. To examine the possibility that the interaction effect was an artifact of scale [51], we performed a sensitivity analysis that modeled our outcome with a poisson distribution and log link. We were heartened to find that our interaction effects were essentially present, even if less strong [see supplementary appendix 1 for further detail].

Future studies should confirm the temporal sequence of these exposures and outcomes we observed. More work is needed to illuminate how depression and alcohol dependence work together in shaping risk for suicidal ideation. For example, substance abuse affects risk of suicidality through changes in executive functioning that result in impulsivity [52,53], but the contours of how exactly this interacts with the neuropsychological deficits inherent in depression [54,55] to shape risk for suicidal ideation is less clear. Finally, it is critical to understand how best to treat those with both conditions and do so with reference to the particular set of circumstances and challenges faced by reservists $[56,57]$. Optimal screening practices for reservists, given their civilian co-status and one weekend per month of military service, remain a challenge. However, evidence based treatments for patients with comorbid alcohol dependence and depression are available [58,59], arguing that such treatments along with appropriate screening be further deployed and utilized for prevention and treatment.

Study limitations include (1) use of telephone interview techniques, a method with less diagnostic validity than clinical interviews; (2) a moderate level of attrition between waves 1 and 2; (3) lack of information on loss to follow-up due to suicide among wave 1 participants; (4) low sensitivity of our outcome measure; (5) a small number of subjects and events across levels of interaction; and (6) quantitative rather than qualitative interaction, raising the possibility of an artifact-based rather than true interaction effect. Despite the inherent limitations with use of telephone interview data, we are reassured about our observations based on a validation study that demonstrated mostly acceptable sensitivity and specificity for the measures used [39]. Although we have a moderate level of attrition between waves 1 and 2, loss to follow up would have to be unequal both by exposure and disease status to affect our odds ratio estimates [60]. Additionally, although loss to follow-up due to suicide is possible among some baseline respondents, this would likely account for only a small percentage of attrition given the low incidence of suicide, and any impact on our effect estimates would likely be negligible or result in an underestimation of our effect measures. Similarly, the low sensitivity of our outcome measure would likely result in an underestimation of our effect estimates. Given knowledge to date on the associations between depression, alcohol misuse and suicide, we would not at all expect a reversal in direction of associations due to any of the above limitations. It is possible that the low sensitivity of our outcome measure threatens inference on the temporal ordering of our exposure outcome relationships, given the possibility that incident cases were truly prevalent cases at baseline. However if this were the case, we do not believe it would change the public health need to identify and treat those with depression, alcohol dependence or both. While the relatively small number of subjects and events did result in estimates with wide confidence intervals, we are confident in our point estimates, and note that the study of suicidal ideation is limited in general given its low frequency. While we are concerned about the difficulty of being confident in quantitative vs. qualitative interaction, we are heartened that our result is unlikely due to measurement scale. We hope that future studies can address these limitations. 


\section{CONCLUSIONS}

Notwithstanding the above limitations, this study suggests a temporal link between coincident alcohol dependence and depression and risk of suicidal ideation; and provides evidence of additive statistical interaction in shaping risk of suicidal ideation. A high-risk suicide prevention strategy that targets military personnel with alcohol dependence, depression, and especially both conditions for screening of suicidal thoughts should receive special attention and further study in suicide prevention efforts. 


\section{References}

1. Kuehn BM (2009) Soldier suicide rates continue to rise. Jama 301 (11):1111-1113

2. Kuehn BM (2010) Military probes epidemic of suicide. Jama 304 (13):1427-1430

3. Kang HK, Bullman TA (2009) Is there an epidemic of suicides among current and former US military personnel? Ann Epidemiol 19 (10):757-760

4. Kang HK, Bullman TA, Smolenski DJ, Skopp NA, Gahm GA, Reger MA (2015) Suicide risk among 1.3 million veterans who were on active duty during the Iraq and Afghanistan wars. Ann Epidemiol 25 (2):96-100

5. Nock MK, Stein MB, Heeringa SG, Ursano RJ, Colpe LJ, Fullerton CS, Hwang I, Naifeh JA, Sampson NA, Schoenbaum M (2014) Prevalence and correlates of suicidal behavior among soldiers: results from the Army Study to Assess Risk and Resilience in Servicemembers (Army STARRS). JAMA psychiatry 71 (5):514-522

6. Reger MA, Smolenski DJ, Skopp NA, Metzger-Abamukang MJ, Kang HK, Bullman TA, Perdue S, Gahm GA (2015) Risk of suicide among US military service members following Operation Enduring Freedom or Operation Iraqi Freedom deployment and separation from the US military. JAMA psychiatry 72 (6):561-569

7. Smolenski D, Reger M, Bush N, Skopp N, Zhang Y, Campise R (2014) Department of Defense Suicide Event Report (DoDSER): Calendar year 2014 annual report. Washington, DC: US Department of Defense 8. Ramchand R, Acosta J, Burns RM (2011) The war within: Preventing suicide in the US military. Rand Corporation, 9. Kinn JT, Luxton DD, Reger MA, Gahm GA, Skopp NA, Bush NE (2011) Department of Defense Suicide Event Report (DoDSER) Calendar Year 2010 Annual Report. DTIC Document, 10. Luxton DD, Osenbach JE, Reger MA, Smolenski DJ, Skopp NA, Bush NE, Gahm GA (2012) Department of Defense Suicide Event Report (DoDSER) Calendar Year 2011 Annual Report. DTIC Document,

11. Griffith J (2016) A Description of Suicides in the Army National Guard During 20072014 and Associated Risk Factors. Suicide and life-threatening behavior

12. Griffith J (2012) Suicide in the Army National Guard: an empirical inquiry. Suicide and life-threatening behavior 42 (1):104-119

13. LeardMann CA, Powell TM, Smith TC, Bell MR, Smith B, Boyko EJ, Hooper TI, Gackstetter GD, Ghamsary M, Hoge CW (2013) Risk factors associated with suicide in current and former US military personnel. Jama 310 (5):496-506

14. Bryan CJ, Griffith JE, Pace BT, Hinkson K, Bryan AO, Clemans TA, Imel ZE (2015) Combat Exposure and Risk for Suicidal Thoughts and Behaviors Among Military Personnel and Veterans: A Systematic Review and Meta - Analysis. Suicide and Life-Threatening Behavior 45 (5):633-649

15. McFarland BH, Kaplan MS, Huguet N (2010) Datapoints: self-inflicted deaths among women with US military service: a hidden epidemic? Psychiatr Serv 16. Harris EC, Barraclough B (1997) Suicide as an outcome for mental disorders. A metaanalysis. The British Journal of Psychiatry 170 (3):205-228 17. Kessler RC, Borges G, Walters EE (1999) Prevalence of and risk factors for lifetime suicide attempts in the National Comorbidity Survey. Arch Gen Psychiatry 56 (7):617-626 
18. Waller SJ, Lyons JS, Costantini-Ferrando MF (1999) Impact of comorbid affective and alcohol use disorders on suicidal ideation and attempts. Journal of clinical psychology 55 (5):585-595

19. Pietrzak RH, Goldstein MB, Malley JC, Rivers AJ, Johnson DC, Southwick SM (2010) Risk and protective factors associated with suicidal ideation in veterans of Operations Enduring Freedom and Iraqi Freedom. J Affect Disord 123 (1):102-107

20. Lemaire CM, Graham DP (2011) Factors associated with suicidal ideation in OEF/OIF veterans. J Affect Disord 130 (1):231-238

21. Cohen GH, Fink DS, Sampson L, Galea S (2015) Mental health among reserve component military service members and veterans. Epidemiol Rev:mxu007

22. Pietrzak RH, Russo AR, Ling Q, Southwick SM (2011) Suicidal ideation in treatmentseeking Veterans of Operations Enduring Freedom and Iraqi Freedom: The role of coping strategies, resilience, and social support. J Psychiatr Res 45 (6):720-726

23. Calabrese JR, Prescott M, Tamburrino M, Liberzon I, Slembarski R, Goldmann E, Shirley E, Fine T, Goto T, Wilson K (2011) PTSD comorbidity and suicidal ideation associated with PTSD within the Ohio Army National Guard. J Clin Psychiatry 72 (8):1,478-1078

24. Jakupcak M, Cook J, Imel Z, Fontana A, Rosenheck R, McFall M (2009) Posttraumatic stress disorder as a risk factor for suicidal ideation in Iraq and Afghanistan war veterans. J Trauma Stress 22 (4):303-306

25. Berglund M, Ojehagen A (1998) The influence of alcohol drinking and alcohol use disorders on psychiatric disorders and suicidal behavior. Alcoholism: Clinical and Experimental Research 22 (S7):333s-345s

26. Cherpitel CJ, Borges GL, Wilcox HC (2004) Acute alcohol use and suicidal behavior: a review of the literature. Alcoholism: Clinical and Experimental Research 28 (s1):18S-28S 27. Pompili M, Serafini G, Innamorati M, Dominici G, Ferracuti S, Kotzalidis GD, Serra G, Girardi P, Janiri L, Tatarelli R (2010) Suicidal behavior and alcohol abuse. Int J Environ Res Public Health 7 (4):1392-1431

28. Hufford MR (2001) Alcohol and suicidal behavior. Clin Psychol Rev 21 (5):797-811 29. Jacobson IG, Ryan MA, Hooper TI, Smith TC, Amoroso PJ, Boyko EJ, Gackstetter GD, Wells TS, Bell NS (2008) Alcohol use and alcohol-related problems before and after military combat deployment. Jama 300 (6):663-675

30. Cornelius JR, Salloum IM, Mezzich J, Cornelius MD, Fabrega Jr H, Ehler JG, Ulrich RF, Thase ME, Mann JJ (1995) Disproportionate suicidality in patients with comorbid major depression and alcoholism. American Journal of Psychiatry 152 (3):358-364 31. Seal KH, Cohen G, Waldrop A, Cohen BE, Maguen S, Ren L (2011) Substance use disorders in Iraq and Afghanistan veterans in VA healthcare, 2001-2010: Implications for screening, diagnosis and treatment. Drug Alcohol Depend 116 (1):93-101 32. Seal KH, Metzler TJ, Gima KS, Bertenthal D, Maguen S, Marmar CR (2009) Trends and risk factors for mental health diagnoses among Iraq and Afghanistan veterans using Department of Veterans Affairs health care, 2002-2008. Am J Public Health 99 (9):16511658

33. Research TAAfPO (2015) Standard Definitions: Final Dispositions of Case Codes and Outcome Rates for Surveys. 8th edn., 34. Vogt DS, Proctor SP, King DW, King LA, Vasterling JJ (2008) Validation of scales from the Deployment Risk and Resilience Inventory in a sample of Operation Iraqi Freedom veterans. Assessment 15 (4):391-403 
35. Breslau N, Kessler RC, Chilcoat HD, Schultz LR, Davis GC, Andreski P (1998) Trauma and posttraumatic stress disorder in the community: the 1996 Detroit Area Survey of Trauma. Arch Gen Psychiatry 55 (7):626-632

36. Kroenke K, Strine TW, Spitzer RL, Williams JB, Berry JT, Mokdad AH (2009) The PHQ-8 as a measure of current depression in the general population. J Affect Disord 114 (1):163173

37. Kroenke K, Spitzer RL, Williams JB (2001) The PHQ-9: Validity of a brief depression severity measure. J Gen Intern Med 16 (9):606-613

38. APA (2000) Diagnostic and statistical manual-text revision (DSM-IV-TR). American Psychiatric Association, Washington, DC

39. Prescott MR, Tamburrino M, Calabrese JR, Liberzon I, Slembarski R, Shirley E, Fine T, Goto T, Wilson K, Ganocy S (2014) Validation of lay - administered mental health assessments in a large Army National Guard cohort. International journal of methods in psychiatric research 23 (1):109-119

40. Sheehan DV, Lecrubier Y, Sheehan KH, Amorim P, Janavs J, Weiller E, Hergueta T, Baker R, Dunbar GC (1998) The Mini-International Neuropsychiatric Interview (MINI): the development and validation of a structured diagnostic psychiatric interview for DSM-IV and ICD-10. Journal of clinical psychiatry

41. Lundberg M, Fredlund P, Hallqvist J, Diderichsen F (1996) A SAS program calculating three measures of interaction with confidence intervals. Epidemiology 7 (6):655-656 42. Rothman KJ, Greenland S, Lash TL (2008) Modern epidemiology. Lippincott Williams \& Wilkins, 43. Rothman KJ, Greenland S, Walker AM (1980) Concepts of interaction. Am J Epidemiol $112(4): 467-470$ 44. SUDAAN (2012). 11 edn. Research Triangle Institute, Research Triangle Park, NC 45. SAS (2012). 9.4 edn. SAS Institute, Cary, NC 46. Kline A, Ciccone DS, Falca-Dodson M, Black CM, Losonczy M (2011) Suicidal ideation among National Guard troops deployed to Iraq: The association with postdeployment readjustment problems. J Nerv Ment Dis 199 (12):914-920

47. Brady J (2006) The association between alcohol misuse and suicidal behaviour. Alcohol Alcohol 41 (5):473-478

48. Modesto-Lowe V, Brooks D, Ghani M (2006) Alcohol dependence and suicidal behavior: from research to clinical challenges. Harv Rev Psychiatry 14 (5):241-248

49. Bertolote JM, Fleischmann A, De Leo D, Wasserman D (2004) Psychiatric diagnoses and suicide: revisiting the evidence. Crisis 25 (4):147-155

50. Knol MJ, VanderWeele TJ, Groenwold RH, Klungel OH, Rovers MM, Grobbee DE (2011) Estimating measures of interaction on an additive scale for preventive exposures.

European journal of epidemiology 26 (6):433-438

51. de González AB, Cox DR (2007) Interpretation of interaction: A review. The Annals of Applied Statistics 1 (2):371-385

52. Griffith J (2015) Relationship of Alcohol Use to Combat Exposure, Post-Traumatic Stress Disorder Symptoms, and Aggressive Behaviors Among Army National Guard OIF/OEF Veterans. Military Behavioral Health 3 (1):64-73 53. Stappenbeck CA, Hellmuth JC, Simpson T, Jakupcak M (2014) The effects of alcohol problems, PTSD, and combat exposure on nonphysical and physical aggression among Iraq 
and Afghanistan war veterans. Psychological trauma: theory, research, practice, and policy $6(1): 65$

54. Keilp JG, Sackeim HA, Brodsky BS, Oquendo MA, Malone KM, Mann JJ (2001)

Neuropsychological dysfunction in depressed suicide attempters. American Journal of Psychiatry 158 (5):735-741

55. Marzuk PM, Hartwell N, Leon A, Portera L (2005) Executive functioning in depressed patients with suicidal ideation. Acta Psychiatr Scand 112 (4):294-301

56. Griffith J (2011) Decades of transition for the US reserves: Changing demands on reserve identity and mental well-being. Int Rev Psychiatry 23 (2):181-191

57. Werber L, Harrell MC, Varda DM, Hall KC, Beckett MK (2009) Deployment experiences of Guard and Reserve families: Implications for support and retention. Rand Corporation, 58. Watkins KE, Hunter SB, Burnam MA, Pincus HA, Nicholson G (2005) Review of treatment recommendations for persons with a co-occurring affective or anxiety and substance use disorder. Psychiatr Serv 56 (8):913-926

59. Tiet QQ, Mausbach B (2007) Treatments for patients with dual diagnosis: a review. Alcoholism: Clinical and Experimental Research 31 (4):513-536

60. Susser E, Schwartz S, Morabia A, Bromet EJ (2006) Psychiatric epidemiology: searching for the causes of mental disorders. Oxford University Press, 
Table 1. Characteristics of study sample of Ohio Army National Guard ( $n=1582)$

Table 2. Bivariable associations between study sample characteristics and suicidal ideation in the Ohio Army National Guard ( $n=1582)$.

Figure 1 - Assessing Interaction Between Alcohol Dependence And Depression In Predicting Incident Suicidal Ideation

Note: All measures reported in figure 1 are weighted, but otherwise unadjusted. 
Table 1. Characteristics of study sample of Ohio Army National Guard ( $n=1582$ )

\begin{tabular}{|c|c|c|c|}
\hline CHARACTERISTICS & Unweighted Ns & $\begin{array}{c}\text { Weighted \% } \\
(95 \% \mathrm{Cl})\end{array}$ & $\begin{array}{c}\text { Design Effects } \\
\text { (subsample) }\end{array}$ \\
\hline \multicolumn{4}{|l|}{ Current Alcohol Dependence $(n=1582)$} \\
\hline No & 1489 & 93.61(92.16-94.81) & \multirow{2}{*}{1.1854} \\
\hline Yes & 93 & $6.39(5.19-7.84)$ & \\
\hline \multicolumn{4}{|l|}{ Current Depression ( $n=1582)$} \\
\hline No & 1418 & $89.50(87.78-91.01)$ & \multirow{2}{*}{1.1353} \\
\hline Yes & 164 & $10.50(8.99-12.22)$ & \\
\hline \multicolumn{4}{|l|}{ Gender $(n=1582)$} \\
\hline Male & 1367 & $86.29(84.40-87.99)$ & \multirow{2}{*}{1.1190} \\
\hline Female & 215 & $13.71(12.01-15.60)$ & \\
\hline \multicolumn{4}{|l|}{ Age $(n=1582)$} \\
\hline $18-24$ & 490 & $37.26(34.64-39.96)$ & 1.2429 \\
\hline $25-34$ & 519 & $34.35(31.87-36.92)$ & 1.1621 \\
\hline $35-44$ & 404 & $20.76(18.88-22.77)$ & 0.9433 \\
\hline $45+$ & 169 & $7.63(6.55-8.87)$ & 0.7773 \\
\hline \multicolumn{4}{|l|}{ Race $(n=1581)^{*}$} \\
\hline White & 1417 & $88.85(86.85-90.58)$ & 1.4337 \\
\hline Black & 100 & $9.56(7.88-11.56)$ & 1.5996 \\
\hline Other & 64 & $1.59(1.24-2.03)$ & 0.4095 \\
\hline \multicolumn{4}{|l|}{ Education $(n=1582)$} \\
\hline High School Graduate /GED or less & 387 & $30.20(27.69-32.84)$ & 1.2982 \\
\hline Some College or Technical Training & 763 & $48.16(45.53-50.81)$ & 1.1496 \\
\hline College/Graduate degree & 432 & 21.64(19.72-23.69) & 0.9537 \\
\hline \multicolumn{4}{|l|}{ Household Income $(n=1540)^{*}$} \\
\hline$<\$ 60,000$ & 868 & $62.01(59.45-64.51)$ & \multirow{2}{*}{1.0878} \\
\hline$>=\$ 60,000$ & 672 & $37.99(35.49-40.55)$ & \\
\hline Marital Status $(n=1581)^{*}$ & & & \\
\hline
\end{tabular}




\begin{tabular}{|c|c|c|c|}
\hline Married & 798 & $40.01(37.56-42.51)$ & 1.0510 \\
\hline Divorced/Separated/Widowed & 146 & $9.40(7.97-11.06)$ & 1.1467 \\
\hline Never Married & 637 & 50.59(47.95-53.23) & 1.1473 \\
\hline \multicolumn{4}{|l|}{ Rank (n=1582) } \\
\hline Officer & 236 & 9.77(8.59-11.10) & \multirow{2}{*}{0.7306} \\
\hline Enlisted, cadets, and civilian employees & 1346 & $90.23(88.90-91.41)$ & \\
\hline \multicolumn{4}{|l|}{ Number of lifetime deployments ( $n=1582$ ) } \\
\hline 0 & 539 & $39.16(36.53-41.84)$ & 1.2174 \\
\hline $1-4$ & 1005 & 58.86(56.17-61.49) & 1.2005 \\
\hline $5+$ & 38 & $1.99(1.44-2.74)$ & 0.8687 \\
\hline \multicolumn{4}{|l|}{$\begin{array}{l}\text { Number of lifetime traumatic events at Wave } 1 \\
(n=1582)\end{array}$} \\
\hline $0-2$ & 297 & $20.19(18.10-22.46)$ & 1.2160 \\
\hline $3-6$ & 451 & $29.37(27.00-31.86)$ & 1.1722 \\
\hline $7-11$ & 409 & $24.97(22.76-27.31)$ & 1.1357 \\
\hline $12+$ & 425 & $25.47(23.28-27.28)$ & 1.0978 \\
\hline \multicolumn{4}{|l|}{$\begin{array}{l}\text { Number of traumatic events between } \\
\text { Wave } 1 \& \text { Wave } 2(n=1582)\end{array}$} \\
\hline 0 & 781 & 49.69(47.05-52.34) & 1.1525 \\
\hline 1 & 346 & $21.55(19.47-23.78)$ & 1.1321 \\
\hline 2 & 182 & $11.53(9.96-13.32)$ & 1.1383 \\
\hline $3+$ & 273 & $17.23(15.31-19.33)$ & 1.1619 \\
\hline \multicolumn{4}{|l|}{ Interaction Indicator Variable ( $n=1582)$} \\
\hline Neither Condition & 1352 & $84.85(82.84-86.66)$ & 1.1622 \\
\hline Alcohol Dependence Alone & 66 & $4.65(3.62-5.95)$ & 1.2315 \\
\hline Depression Alone & 137 & $8.76(7.38-10.38)$ & 1.1476 \\
\hline Alcohol Dependence and Depression & 27 & $1.74(1.18-2.55)$ & 1.0658 \\
\hline \multicolumn{4}{|l|}{ Suicidal Ideation w2 ( $\mathrm{n}=1582)$} \\
\hline Yes & 42 & $2.47(1.68-3.26)$ & \multirow{2}{*}{1.0708} \\
\hline No & 1540 & $97.53(96.74-98.32)$ & \\
\hline
\end{tabular}

* Denotes presence of missing value 
Table 2. Bivariable associations between study sample characteristics and suicidal ideation in the Ohio Army National Guard $(n=1582)$.

\begin{tabular}{|c|c|c|c|c|}
\hline CHARACTERISTICS & $\begin{array}{l}\text { Unweighted } \\
\text { Frequency of } \\
\text { events }\end{array}$ & Weighted \% (95\% Cl) & $\begin{array}{c}\chi^{2} \\
p \text {-value }\end{array}$ & $\begin{array}{c}\text { Crude Weighted OR } \\
(95 \% \mathrm{Cl})\end{array}$ \\
\hline \multicolumn{3}{|l|}{ Current Alcohol Dependence ( $n=1582)$} & \multirow{3}{*}{$\begin{array}{c}\chi^{2}(d f=1)=4.54 \\
p=0.03\end{array}$} & \\
\hline No & 34 & $2.03(1.42-2.89)$ & & 1 \\
\hline Yes & 8 & $8.97(4.41-17.38)$ & & $4.76(2.05-11.06)$ \\
\hline \multicolumn{3}{|l|}{ Current Depression ( $n=1582)$} & \multirow{3}{*}{$\begin{array}{c}\chi^{2}(d f=1)=7.96 \\
p<0.001\end{array}$} & \\
\hline No & 28 & $1.81(1.21-2.70)$ & & 1 \\
\hline Yes & 14 & $8.09(4.74-13.48)$ & & $4.77(2.37-9.63)$ \\
\hline \multicolumn{3}{|l|}{ Gender $(n=1582)$} & \multirow{3}{*}{$\begin{array}{c}\chi^{2}(\mathrm{df}=1)=0.16 \\
p=0.69\end{array}$} & \\
\hline Male & 34 & $2.41(1.68-3.43)$ & & 1 \\
\hline Female & 8 & $2.86(1.37-5.87)$ & & $1.20(0.52-2.75)$ \\
\hline \multicolumn{3}{|l|}{ Age $(n=1582)$} & \multirow{5}{*}{$\begin{array}{c}\chi^{2}(\mathrm{df}=3)=0.26 \\
p=0.86\end{array}$} & \\
\hline $18-24$ & 15 & $2.69(1.58-4.56)$ & & 1 \\
\hline $25-34$ & 11 & $2.00(1.07-3.74)$ & & $0.74(0.32-1.71)$ \\
\hline $35-44$ & 11 & $2.73(1.46-5.02)$ & & $1.01(0.44-2.34)$ \\
\hline $45+$ & 5 & $2.79(1.15-6.60)$ & & $1.04(0.36-2.97)$ \\
\hline \multicolumn{3}{|l|}{ Race $(n=1581)^{*}$} & \multirow{4}{*}{$\begin{array}{c}\chi^{2}(d f=2)=3.15 \\
p=0.21\end{array}$} & \\
\hline White & 38 & $2.60(1.86-3.62)$ & & 1 \\
\hline Black & 1 & $0.95(0.13-6.46)$ & & $0.36(0.05-2.67)$ \\
\hline Other & 3 & $4.57(1.47-13.35)$ & & $1.80(0.53-6.07)$ \\
\hline \multicolumn{3}{|l|}{ Education $(n=1582)$} & \multirow{4}{*}{$\begin{array}{c}\chi^{2}(\mathrm{df}=2)=2.24 \\
\mathrm{p}=0.11\end{array}$} & \\
\hline High School Graduate /GED or less & 6 & $1.34(0.59-3.01)$ & & 1 \\
\hline Some College or Technical Training & 24 & $3.04(1.98-4.63)$ & & $2.31(0.91-5.90)$ \\
\hline College/Graduate degree & 12 & $2.78(1.53-5.03)$ & & $2.11(0.75-5.93)$ \\
\hline \multicolumn{3}{|l|}{ Income $(n=1540)^{*}$} & \multirow{3}{*}{$\begin{array}{c}\chi^{2}(d f=3)=3.55 \\
p=0.06\end{array}$} & \\
\hline$<\$ 60,000$ & 29 & $3.07(2.09-4.47)$ & & $1.94(0.93-4.06)$ \\
\hline$>=\$ 60,000$ & 12 & $1.60(0.86-2.95)$ & & 1 \\
\hline
\end{tabular}


Coincident Alcohol Dependence and Depression

\begin{tabular}{|c|c|c|c|c|}
\hline Marital Status ( $n=1581)^{*}$ & & & \multirow{4}{*}{$\begin{array}{c}\chi^{2}(\mathrm{df}=3)=0.59 \\
p=0.74\end{array}$} & \\
\hline Married & 21 & $2.54(1.63-3.95)$ & & 1 \\
\hline Divorced/Separated/Widowed & 6 & $3.43(1.46-7.84)$ & & $1.36(0.51-3.65)$ \\
\hline Never Married & 15 & $2.24(1.32-3.76)$ & & $0.88(0.43-1.77)$ \\
\hline \multicolumn{3}{|l|}{ Rank ( $n=1582)$} & \multirow{3}{*}{$\begin{array}{c}\chi^{2}(\mathrm{df}=1)=0.24 \\
\mathrm{p}=0.62\end{array}$} & \\
\hline Officer & 5 & $2.02(0.84-4.81)$ & & 1 \\
\hline Enlisted, cadets, and civilian employees & 37 & $2.52(1.79-3.53)$ & & $1.25(0.48-3.27)$ \\
\hline \multicolumn{3}{|l|}{ Number of lifetime deployments ( $n=1582)$} & \multirow{4}{*}{$\begin{array}{c}\chi^{2}(\mathrm{df}=2)=0.81 \\
p=0.44\end{array}$} & \\
\hline 0 & 11 & $2.11(1.14-3.87)$ & & 1 \\
\hline $1-4$ & 28 & $2.53(1.71-3.74)$ & & $1.21(0.57-2.54)$ \\
\hline $5+$ & 3 & 7.78(2.41-22.40) & & $3.92(0.99-15.58)$ \\
\hline \multicolumn{3}{|c|}{ Number of lifetime traumatic events at Wave $1(n=1582)$} & \multirow{5}{*}{$\begin{array}{c}\chi^{2}(\mathrm{df}=3)=1.02 \\
p=0.38\end{array}$} & \\
\hline $0-2$ & 7 & $2.10(0.91-4.80)$ & & 1 \\
\hline $3-6$ & 9 & $1.63(0.82-3.22)$ & & $0.77(0.26-2.32)$ \\
\hline $7-11$ & 12 & $3.01(1.67-5.36)$ & & $1.44(0.51-4.11)$ \\
\hline $12+$ & 14 & $3.21(1.85-5.51)$ & & $1.54(0.55-4.30)$ \\
\hline \multicolumn{3}{|c|}{ Number of traumatic events between Wave 1 \& Wave $2(n=1582$ ) } & \multirow{5}{*}{$\begin{array}{c}\chi^{2}(\mathrm{df}=2)=2.49 \\
\mathrm{p}=0.06\end{array}$} & \\
\hline 0 & 11 & $1.37(0.72-2.56)$ & & 1 \\
\hline 1 & 13 & $3.99(1.90-5.98)$ & & $2.54(1.06-6.08)$ \\
\hline 2 & 8 & $3.93(1.86-8.11)$ & & $2.96(1.09-8.04)$ \\
\hline $3+$ & 10 & $3.52(1.84-6.64)$ & & $2.64(1.05-6.65)$ \\
\hline \multicolumn{3}{|l|}{ Interaction Indicator Variable ( $\mathrm{n}=1582)$} & \multirow{5}{*}{$\begin{array}{c}\chi^{2}(\mathrm{df}=3)=3.43 \\
\mathrm{p}=0.02)\end{array}$} & \\
\hline Neither Condition & 24 & $1.59(1.03-2.44)$ & & 1 \\
\hline Alcohol Dependence Alone & 4 & $5.85(2.04-15.66)$ & & $3.85(1.18-12.52)$ \\
\hline Depression Alone & 10 & $6.26(3.30-11.56)$ & & $4.14(1.86-9.22)$ \\
\hline Alcohol Dependence and Depression & 4 & $17.31(6.66-38.06)$ & & $12.97(4.05-41.47)$ \\
\hline
\end{tabular}

* Denotes presence of missing values 


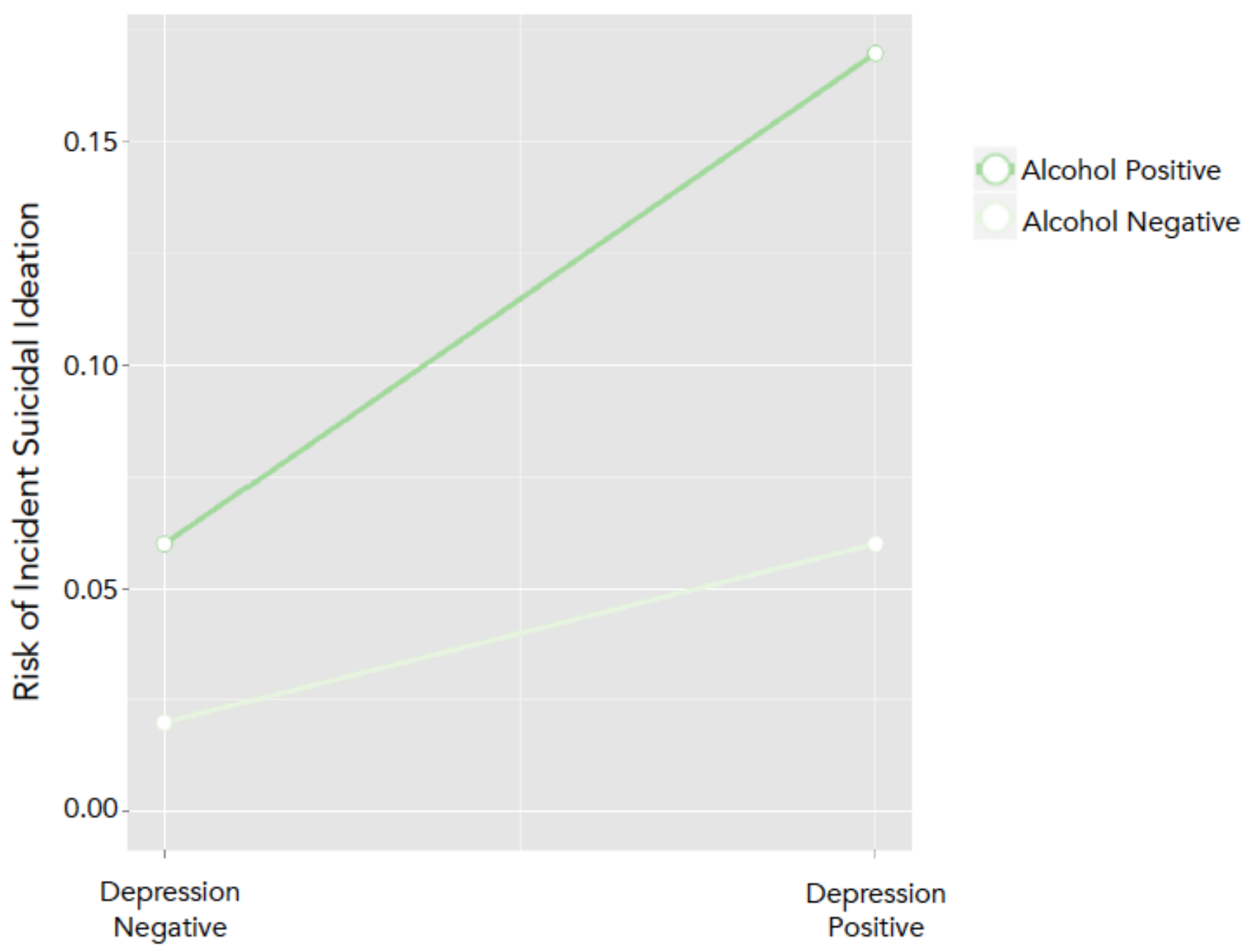

\begin{tabular}{llc} 
Odds Ratio & $3.85(1.18-12.52)$ & $3.13(0.88-11.14)$ \\
\hline Risk Difference & $0.04(0.02-0.07)$ & $0.11(0.06-0.18)$ \\
\hline & Relative Excess Risk of Interaction (RERI) $=5.978(0.364-11.591)$ \\
\hline \multicolumn{2}{c}{ Attributable Proportion Due to Interaction $=0.461(0.199-0.723)$} \\
\hline \multicolumn{2}{c}{ Synergy Index = 1.998 $(1.163-3.434)$} \\
\hline
\end{tabular}

Figure 1 - Assessing Interaction Between Alcohol Dependence And Depression In Predicting Incident Suicidal Ideation Note: All measures reported in figure 1 are weighted, but otherwise unadjusted. 